\title{
Mycobacterium bovis Bacillus Calmette-Guérin-Induced Macrophage Cytotoxicity against Bladder Cancer Cells
}

\author{
Yi Luo and Matthew J. Knudson \\ Department of Urology, University of Iowa, 375 Newton Road, 3202 MERF, Iowa City, IA 52242, USA \\ Correspondence should be addressed to Yi Luo, yi-luo@uiowa.edu
}

Received 15 June 2010; Accepted 16 August 2010

Academic Editor: Bernhard Fleischer

Copyright (๑) 2010 Y. Luo and M. J. Knudson. This is an open access article distributed under the Creative Commons Attribution License, which permits unrestricted use, distribution, and reproduction in any medium, provided the original work is properly cited.

\begin{abstract}
Many details of the molecular and cellular mechanisms involved in Mycobacterium bovis bacillus Calmette-Guérin (BCG) immunotherapy of bladder cancer have been discovered in the past decades. However, information on a potential role for macrophage cytotoxicity as an effector mechanism is limited. Macrophages play pivotal roles in the host innate immunity and serve as a first line of defense in mycobacterial infection. In addition to their function as professional antigen-presenting cells, the tumoricidal activity of macrophages has also been studied with considerable interest. Studies have shown that activated macrophages are potent in killing malignant cells of various tissue origins. This review summarizes the current understanding of the BCG-induced macrophage cytotoxicity toward bladder cancer cells with an intention to inspire investigation on this important but underdeveloped research field.
\end{abstract}

\section{Role of Macrophages in BCG Immunotherapy of Bladder Cancer}

Intravesical instillation of BCG is used for the treatment of superficial transitional cell carcinoma (TCC) of the bladder to reduce recurrence and progression of this disease. Since its first therapeutic application in 1976 [1], major efforts have been directed to decipher the mechanisms through which BCG mediates antibladder cancer immunity. Although the exact mechanism of BCG action remains elusive, an induction of localized cellular immune responses reflecting activation of various types of immune cells has been proposed $[2,3]$. Potential effector cells responsible for tumor killing include MHC-restricted cytotoxic T cells $\left(\mathrm{CD} 8^{+} \mathrm{CTL}\right)$ and $\mathrm{CD} 4^{+} \mathrm{T}$ cells $[4,5], \mathrm{MHC}$-nonrestricted cells such as natural killer (NK) cells [6-8], lymphokineactivated killer (LAK) cells $[8,9]$ and BCG-activated killer (BAK) cells [10-12], CD1-restricted $\mathrm{CD}^{+} \mathrm{T}$ cells [13], $\gamma \delta \mathrm{T}$ cells [14-16], natural killer $\mathrm{T}$ (NKT) cells [15-17], neutrophils $[18,19]$, and macrophages [20-22]. Several lines of evidence suggest that macrophages actively mediate antibladder cancer immunity induced by BCG. Following BCG instillation, increased numbers of macrophages, along with T cells, NK cells, dendritic cells (DC), and neutrophils, were observed in bladder cancer infiltrates and the peritumoral bladder wall [2, 3, 23-26]. The voided urine of bladder cancer patients after BCG treatment also contained increased numbers of macrophages and other types of immune cells [27-29]. Moreover, a transient secretion of various cytokines and chemokines in patients' urine after intravesical BCG treatment has been reported, including those predominantly produced by macrophages such as TNF- $\alpha$, IL-6, IL-10, IL12 , and IL-18 [2, 3, 29-35]. Furthermore, both human and murine macrophages have been observed to produce TNF- $\alpha$, IFN- $\gamma$, IL-6, IL-10, IL-12, and IL-18 in response to BCG stimulation in vitro [36-39]. In addition to their cytokine/chemokine production, both human and murine macrophages can also act as cytotoxic effector cells toward bladder cancer cells upon activation by BCG in vitro [40-46]. It has been postulated that, in the case of intravesical BCG treatment of bladder cancer, the bladder mucosa develops BCG-mediated inflammatory responses, which involve the initial binding of BCG to fibronectin on the urothelium [47], followed by internalization of BCG by urothelial cells, and subsequent activation of various immune cells including macrophages in the bladder wall $[47,48]$. Once activated 
by BCG, macrophages gain effector functions to act as inflammatory, microbicidal, and tumoricidal cells in BCGinduced anti-bladder cancer immune responses.

\section{BCG-Induced Macrophage Cytotoxicity}

The BCG induction of macrophage cytotoxicity can be demonstrated in vitro through a cytotoxicity assay in which macrophages are preactivated with BCG and then coincubated with radioisotope-labeled bladder cancer cells, followed by analysis of radioisotope release from target cells in culture supernatants. Using this method, Pryor and associates reported that BCG could enhance monocytes/macrophages from human peripheral blood to kill bladder cancer UCRU-BL-17 cells [40]. Although naïve monocytes/ macrophages exhibited minimum cytotoxicity, the cytotoxic activity of the cells was significantly enhanced upon BCG stimulation. In addition, BCG appeared to be superior to IFN- $\alpha$, IFN- $\gamma$, and IL-2 in enhancing monocyte/ macrophage-mediated cytotoxicity. However, the BCGactivated monocytes/macrophages failed to show consistent cytotoxicity toward bladder cancer 5637, T24, and J82 cells, although all these cell lines including UCRU-BL-17 were similarly susceptible to BCG direct killing [40]. Possible explanations for this discrepancy might relate to differential expression of the receptors of cytotoxic effector molecules on target cells or adhesion molecules on both effector and target cells. These possibilities wait to be investigated.

Yamada and associates reported that thioglycollateelicited peritoneal macrophages from $\mathrm{C} 3 \mathrm{H} / \mathrm{HeN}$ mice were cytotoxic to syngeneic bladder cancer MBT-2 cells upon BCG stimulation [41-43]. This BCG-induced macrophage cytotoxicity was correlated with the production of TNF- $\alpha$, IFN$\gamma$, and IL-12 by macrophages. In addition, viable BCG was observed to be superior to nonviable BCG for the induction of macrophage cytotoxic activity and cytokine production $[42,43]$. Yamada and associates further observed that $\mathrm{C} 3 \mathrm{H} / \mathrm{HeN}$ macrophages produced prostaglandin $(\mathrm{PG}) \mathrm{E}_{2}$ along with other cytokines in response to BCG stimulation [43]. $\mathrm{PGE}_{2}$ exhibited an inhibitory effect on BCG-induced $\mathrm{C} 3 \mathrm{H} / \mathrm{HeN}$ macrophage cytotoxicity toward MBT-2 cells [43]. Inhibition of cyclooxygenase (COX)-1 and/or COX-2, the enzymes responsible for the formation of prostanoids such as $\mathrm{PGE}_{2}$ [49], during BCG stimulation could enhance the macrophage cytotoxic activity and production of TNF- $\alpha$ and IFN- $\gamma$ [43]. These observations suggested that an inhibitor of PG synthesis might be potentially useful for enhancing BCG immunotherapy of bladder cancer. Subsequently, our own studies demonstrated the ability of BCG to induce the cytotoxic activity of $\mathrm{C} 3 \mathrm{H} / \mathrm{HeN}$ macrophages toward MBT-2 cells [44-46]. We were able to show that BCG was superior to lipopolysaccharide (LPS) for the induction of macrophage cytotoxicity $[45,46]$. Our investigations further demonstrated that endogenous T helper type (Th) 1 cytokines IFN$\gamma$, IL-12, and IL-18 as well as proinflammatory cytokine TNF- $\alpha$ played an important role in BCG-induced C3H/HeN macrophage cytotoxicity and that supplementation of BCG with exogenous recombinant (r) IL-12 and rIL-18 could enhance the macrophage cytotoxicity [45].
In addition to $\mathrm{C} 3 \mathrm{H} / \mathrm{HeN}$ macrophages, we have also observed that BCG could induce cytotoxic activity of macrophages from C57BL/6 mice toward syngeneic bladder cancer MB49 cells [46]. Further, both BCG-activated C3H/ $\mathrm{HeN}$ macrophages and BCG-activated C57BL/6 macrophages were capable of killing allogeneic bladder cancer cells reciprocally, although such killing was less potent than those toward syngeneic bladder cancer cells [46]. Compared to BCG-activated $\mathrm{C} 3 \mathrm{H} / \mathrm{HeN}$ macrophages, the cytotoxic activity of BCG-activated C57BL/6 macrophages was substantially weak. Since both MBT-2 cells and MB49 cells showed similar susceptibility to macrophage-derived cytotoxic effector molecules such as TNF- $\alpha$ and nitric oxide (NO) [46], Th2 cytokine(s) produced by BCG-activated macrophages might be causative for the reduced cytotoxicity of C57BL/6 macrophages. To determine this, we conducted a study in which macrophages of both genetic backgrounds were assessed in parallel for their cytokine and NO production [46]. We found that macrophage-derived IL-10 played an inhibitory role in BCG-induced macrophage cytotoxicity and was responsible for the BCG induction of reduced cytotoxic activity of C57BL/6 macrophages [46]. However, differential expression of IL-10 receptors on bladder cancer cells and/or macrophages from the two different genetic backgrounds might also play a role in susceptibility of the tumor cells to BCG-induced macrophage cytotoxicity. Thus, although both MBT-2 cell and MB49 cell-derived bladder cancers in syngeneic mice, two widely used bladder cancer models, have been demonstrated to be similarly responsive to intravesical BCG treatment [50, 51], the detailed mechanisms through which BCG induces antitumor immunity in these two distinctive genetic backgrounds of mice are apparently not identical.

\section{Mechanism of BCG-Induced Macrophage Cytotoxicity}

Multiple effector mechanisms are involved in the killing of bladder cancer cells by BCG-induced macrophage cytotoxicity. Both direct effector-target cell contact and release of soluble cytotoxic factors (such as TNF- $\alpha$, IFN- $\gamma$ and NO) are required for effective killing of bladder cancer cells by BCGactivated macrophages [45]. The effector-target cell contact was observed to contribute to approximately $50 \%$ of the total killing of MBT-2 cells by BCG-activated C3H/HeN macrophages [45]. However, knowledge about the mechanism of cell-cell contact mediated killing is scarce. BCG infection may result in up-regulated expression of adhesion molecules such as lymphocyte function-associated antigen-1 (LFA-1) or apoptosis-inducing molecules such as Fas ligand and TRAIL on macrophages [52-54]. Acquirement of these surface molecules could direct macrophages to bind to and kill bladder cancer cells. This assumption of phenotypical changes of macrophages has been a subject of study that should yield valuable insights into the mechanism of BCG action.

Soluble factors released from macrophages were also found to account for approximately $50 \%$ of the total killing of MBT-2 cells by BCG-activated $\mathrm{C} 3 \mathrm{H} / \mathrm{HeN}$ macrophages 
[45]. Soluble factors released from BCG-activated human monocytes/macrophages contributed to the total killing of UCRU-BL-17 cells even higher than effector-target cell contact [40]. Production of TNF- $\alpha$, IFN- $\gamma$, and NO by macrophages in response to BCG stimulation has been observed in vitro [36-39, 41-46, 55, 56]. These effector factors are known to be cytotoxic to bladder cancer cells $[45,46,57-59]$ and kill target cells through the apoptotic and/or necrotic pathways [60-62]. In addition to the killing of bladder cancer cells, both TNF- $\alpha$ and IFN- $\gamma$ are also known to work through autocrine for macrophage activation and $\mathrm{NO}$ production $[38,56,63-65]$. NO is a reactive nitrogen/oxygen intermediate with strong cytotoxicity toward malignant cells. It has been demonstrated to kill both human and murine bladder cancer cells in vitro [46, 66-68]. Thus, production of TNF- $\alpha$, IFN- $\gamma$, and NO renders macrophages activation and cytotoxic activity. Indeed, high BCG-induced macrophage cytotoxicity has been observed to correlate with high production of these cytotoxic effector molecules [ 45 , 46].

\section{Role of Th1 and Th2 Cytokines in BCG-Induced Macrophage Cytotoxicity}

Macrophages produce inflammatory cytokines, such as TNF$\alpha$, IFN- $\gamma$, IL-6, IL-10, IL-12, and IL-18, in response to BCG stimulation [36-39, 41-46]. These cytokines act in a reciprocal fashion and are tightly controlled for a proper induction of Th1/Th2 immune responses. Acquirement of a Th1 immune response is essential to effective BCG immunotherapy of bladder cancer $[2,3,32-34,69]$. In addition, Th1 cytokines are also found to be vital for the BCG induction of macrophage tumoricidal activity.

4.1. Role of Th1 Cytokines. It has been observed that Th1 cytokines IFN- $\gamma$, IL-12, and IL-18 play a positive role in BCG-induced macrophage cytotoxicity toward bladder cancer cells $[43,45]$. Proinflammatory cytokine TNF$\alpha$ has also been observed to be critical in the BCGinduced macrophage cytotoxicity $[43,45]$. Blockage of these endogenous cytokines by neutralizing antibodies significantly reduced BCG-induced $\mathrm{C} 3 \mathrm{H} / \mathrm{HeN}$ macrophage cytotoxicity toward MBT-2 cells [43, 45]. Among these cytokines, neutralization of TNF- $\alpha$ led to the most severe inhibition on macrophage cytotoxicity [45]. To support this role of Th1 cytokines, it has been observed that supplementation of BCG with exogenous rIL-12 or rIL-18 resulted in an increase in the induction of macrophage cytotoxicity [45]. Moreover, $\mathrm{C} 3 \mathrm{H} / \mathrm{HeN}$ macrophages treated with $\mathrm{rBCG}$ expressing IL18 exhibited increased killing of MBT-2 cells, along with increased production of TNF- $\alpha$ and IFN- $\gamma$ [44, 45]. In addition, $\mathrm{C} 3 \mathrm{H} / \mathrm{HeN}$ macrophages developed enhanced cytotoxicity after stimulation with BCG plus rIL-2 or with rBCG expressing IL-2 $[41,45]$. These observations suggest that Th1 cytokines play a pivotal role in BCG-induced macrophage cytotoxicity and that combination of BCG with Th1 cytokines may enhance the effect of BCG in the treatment of bladder cancer patients.
4.2. Role of Th2 Cytokines. IL-10, one of the major Th2 cytokines produced by macrophages, is inhibitory to the BCG induction of macrophage cytotoxicity. High IL-10 production was observed to correlate with low killing of MB49 cells and reduced production of TNF- $\alpha$, IL- 6 , and NO by BCG-activated C57BL/6 macrophage [46]. To support this inhibitory role of IL-10, neutralizing endogenous IL-10 during BCG stimulation resulted in increased BCG-induced C57BL/6 macrophage cytotoxicity toward MB49 cells, along with increased production of TNF- $\alpha$ and NO [46]. Since supplementation of exogenous rTNF- $\alpha$ failed to enhance the BCG-induced macrophage cytotoxicity, IL-10 appeared to play a predominant role in controlling the induction of C57BL/6 macrophage cytotoxicity by BCG [46]. Further evidence supporting the inhibitory role of IL-10 includes the studies that showed high BCG-induced cytotoxicity toward MB49 cells by macrophages from genetically modified C57BL/6 mice lacking IL-10 (IL-10 $0^{-/-}$) and reduced BCGinduced cytotoxicity toward MBT-2 cells as well as MB49 cells by $\mathrm{C} 3 \mathrm{H} / \mathrm{HeN}$ macrophages pretreated with exogenous rIL-10 [46]. In addition, studies have also shown that IL-10 could inhibit macrophage release of cytokines (e.g., TNF$\alpha$ ) and reactive nitrogen/oxygen intermediates (e.g., NO) [70-73]. Thus, IL-10 is inhibitory to the inflammatory, microbicidal and tumoricidal activities of macrophages. These observations suggest that blockage of IL-10 may potentially enhance the effect of BCG in the treatment of bladder cancer patients, particularly for BCG nonresponders who often develop high IL-10 levels during BCG treatment [32-34].

The role of IL-6 in BCG-induced macrophage cytotoxicity remains elusive. Production of IL-6, along with TNF- $\alpha$, IFN- $\gamma$, and NO, was observed to correlate with the BCG induction of cytotoxic activity of both $\mathrm{C} 3 \mathrm{H} / \mathrm{HeN}$ macrophages and C57BL/6 macrophages [45, 46]. IL-6 is known to be involved in macrophage maturation [74], and thus may contribute to BCG-induced macrophage cytotxicity through its influence on macrophage release of cytotoxic effector molecules and/or expression of surface adhesion and apoptosis-inducing molecules. In addition, the fates of supplementation of exogenous rIL- 6 or blockage of endogenous IL-6 on BCG induction of macrophage cytotoxicity are unknown.

\section{Conclusion and Future View}

In vitro studies have demonstrated the ability of BCG to induce macrophage cytotoxicity toward bladder cancer cells in both human and murine. This macrophage-mediated killing of bladder cancer cells depends on both direct effector-target cell contact and release of soluble cytotoxic factors, such as TNF- $\alpha$, IFN- $\gamma$, and NO, from macrophages. Th1 cytokines IFN- $\gamma$, IL-12, and IL-18 as well as proinflammatory cytokine TNF- $\alpha$ play positive roles in BCG-induced macrophage cytotoxicity whereas Th2 cytokine IL-10 plays a negative role in BCG-induced macrophage cytotoxicity. Supplementation of exogenous Th1 cytokines such as rIL-12 and rIL-18 or inhibition of endogenous Th2 cytokine IL-10 enhances BCG-induced macrophage cytotoxicity. However, 
despite these findings, there are some unsolved issues with respect to the BCG-induced macrophage cytotoxicity: (1) how potent is the cytotoxic activity of macrophages relative to T cells, NK cells, LAK cells, BAK cells, and NKT cells in killing bladder cancer cells?, (2) what are the phenotypical changes of macrophages in response to BCG stimulation that facilitate macrophages to contact bladder cancer cells?, (3) why do BCG-activated macrophages exhibit no cytotoxicity toward some human bladder cancer cell lines?, and (4) what is the actual role of IL-6 in BCG-induced macrophage cytotoxicity toward bladder cancer cells? In addition, although BCG-induced macrophage cytotoxicity has been demonstrated in vitro, there is a lack of evidence supporting the role of macrophage cytotoxicity in BCG-mediated eradication of bladder cancer in vivo. As technology develops, we anticipate that these issues will be approached and answered. A better understanding of the role of macrophages in BCG mediated immune responses will no doubt add to our proper design and application of BCG immunotherapy for bladder cancer.

\section{References}

[1] A. Morales, D. Eidinger, and A. W. Bruce, "Intracavitary Bacillus Calmette Guerin in the treatment of superficial bladder tumors," Journal of Urology, vol. 116, no. 2, pp. 180$183,1976$.

[2] A. B. Alexandroff, A. M. Jackson, M. A. O’Donnell, and K. James, "BCG immunotherapy of bladder cancer: 20 years on," Lancet, vol. 353, no. 9165, pp. 1689-1694, 1999.

[3] J. J. Patard, F. Saint, F. Velotti, C. C. Abbou, and D. K. Chopin, "Immune response following intravesical bacillus CalmetteGuerin instillations in superficial madder cancer: a review," Urological Research, vol. 26, no. 3, pp. 155-159, 1998.

[4] T. L. Ratliff, J. K. Ritchey, J. J. J. Yuan, G. L. Andriole, and W. J. Catalona, "T-cell subsets required for intravesical BCG immunotherapy for bladder cancer," Journal of Urology, vol. 150, no. 3, pp. 1018-1023, 1993.

[5] R. Wang, A. M. Rogers, T. L. Ratliff, and J. H. Russell, "CD95-dependent bystander lysis caused by CD4+ T helper 1 effectors," Journal of Immunology, vol. 157, no. 7, pp. 29612968, 1996.

[6] S. Brandau, J. Riemensberger, M. Jacobsen et al., "NK cells are essential for effective BCG immunotherapy," International Journal of Cancer, vol. 92, no. 5, pp. 697-702, 2001.

[7] W. Liu, M. A. O'Donnell, X. Chen, R. Han, and Y. Luo, "Recombinant bacillus Calmette-Guérin (BCG) expressing interferon-alpha 2B enhances human mononuclear cell cytotoxicity against bladder cancer cell lines in vitro," Cancer Immunology, Immunotherapy, vol. 58, no. 10, pp. 1647-1655, 2009.

[8] M.-H. Wang, H.-D. Flad, A. Böhle, Y.-Q. Chen, and A. J. Ulmer, "Cellular cytotoxicity of human natural killer cells and lymphokine-activated killer cells against bladder carcinoma cell lines," Immunology Letters, vol. 27, no. 3, pp. 191-198, 1991.

[9] M. M. Shemtov, D. L.-W. Cheng, L. Kong et al., "LAK cell mediated apoptosis of human bladder cancer cells involves a $\mathrm{pH}$-dependent endonuclease system in the cancer cell: possible mechanism of BCG therapy," Journal of Urology, vol. 154, no. 1, pp. 269-274, 1995.

[10] A. Thanhäuser, A. Böhle, H.-D. Flad, M. Ernst, T. Mattern, and A. J. Ulmer, "Induction of bacillus-Calmette-Guerin-activated killer cells from human peripheral blood mononuclear cells against human bladder carcinoma cell lines in vitro," Cancer Immunology Immunotherapy, vol. 37, no. 2, pp. 105-111, 1993.

[11] S. Brandau, H. Suttmann, J. Riemensberger et al., "Perforinmediated lysis of tumor cells by Mycobacterium Bovis Bacillus Calmette-Guerin-activated killer cells," Clinical Cancer Research, vol. 6, no. 9, pp. 3729-3738, 2000.

[12] A. Böhle, A. Thanhäuser, A. J. Ulmer, M. Ernst, H.-D. Flad, and D. Jocham, "Dissecting the immunobiological effects of Bacillus Calmette-Guerin (BCG) in vitro: evidence of a distinct BCG-activated killer (BAK) cell phenomenon," Journal of Urology, vol. 150, no. 6, pp. 1932-1937, 1993.

[13] T. Kawashima, Y. Norose, Y. Watanabe et al., "Cutting edge: major CD8 T cell response to live bacillus Calmette-Guérin is mediated by CD1 molecules," Journal of Immunology, vol. 170, no. 11, pp. 5345-5348, 2003.

[14] M.-H. Wang, Y.-Q. Chen, J. Gercken et al., "Specific activation of human peripheral blood $\gamma / \delta+$ T lymphocytes by sonicated antigens of Mycobacterium tuberculosis: role in vitro in killing human bladder carcinoma cell lines," Scandinavian Journal of Immunology, vol. 38, no. 3, pp. 239-246, 1993.

[15] T. Higuchi, M. Shimizu, A. Owaki et al., "A possible mechanism of intravesical BCG therapy for human bladder carcinoma: involvement of innate effector cells for the inhibition of tumor growth," Cancer Immunology, Immunotherapy, vol. 58, no. 8, pp. 1245-1255, 2009.

[16] M. Naoe, Y. Ogawa, K. Takeshita et al., "Bacillus CalmetteGuérin-pulsed dendritic cells stimulate natural killer T cells and $\gamma \delta \mathrm{T}$ cells," International Journal of Urology, vol. 14, no. 6 , pp. 532-538, 2007.

[17] M. Emoto, Y. Emoto, I. B. Buchwalow, and S. H. E. Kaufmann, "Induction of IFN- $\gamma$-producing CD4+ natural killer T cells by Mycobacterium bovis bacillus Calmette Guerin," European Journal of Immunology, vol. 29, no. 2, pp. 650-659, 1999.

[18] H. Suttmann, J. Riemensberger, G. Bentien et al., "Neutrophil granulocytes are required for effective Bacillus CalmetteGuérin immunotherapy of bladder cancer and orchestrate local immune responses," Cancer Research, vol. 66, no. 16, pp. 8250-8257, 2006.

[19] H. M. Rosevear, A. J. Lightfoot, M. A. O’Donnell, and T. S. Griffith, "The role of neutrophils and TNF-related apoptosisinducing ligand (TRAIL) in bacillus Calmette-Guérin (BCG) immunotherapy for urothelial carcinoma of the bladder," Cancer Metastasis Reviews, vol. 28, no. 3-4, pp. 345-353, 2009.

[20] J. Klostergaard, P. A. Stoltje, and F. C. Kull Jr., "Tumoricidal effector mechanisms of murine BCG-activated macrophages: role of TNF in conjugation-dependent and conjugationindependent pathways," Journal of Leukocyte Biology, vol. 48, no. 3, pp. 220-228, 1990.

[21] J. Klostergaard, M. E. Leroux, and M.-C. Hung, "Cellular models of macrophage tumoricidal effector mechanisms in vitro. Characterization of cytolytic responses to tumor necrosis factor and nitric oxide pathways in vitro," Journal of Immunology, vol. 147, no. 8, pp. 2802-2808, 1991.

[22] G. Schwamberger, I. Flesch, and E. Ferber, "Tumoricidal effector molecules of murine macrophages," Pathobiology, vol. 59, no. 4, pp. 248-253, 1991.

[23] A. Böhle, J. Gerdes, A. J. Ulmer, A. G. Hofstetter, and H.D. Flad, "Effects of local bacillus Calmette-Guerin therapy in patients with bladder carcinoma on immunocompetent cells of the bladder wall," Journal of Urology, vol. 144, no. 1, pp. 53$58,1990$.

[24] S. Prescott, K. James, T. B. Hargreave, G. D. Chisholm, and J. F. Smyth, "Intravesical Evans strain BCG therapy: 
quantitative immunohistochemical analysis of the immune response within the bladder wall," Journal of Urology, vol. 147, no. 6, pp. 1636-1642, 1992.

[25] M. Peuchmaur, G. Benoit, A. Vieillefond et al., "Analysis of mucosal bladder leucocyte subpopulations in patients treated with intravesical bacillus calmette-guerin," Urological Research, vol. 17, no. 5, pp. 299-303, 1989.

[26] F. Saint, J. J. Patard, B. Groux Muscatelli et al., "Evaluation of cellular tumour rejection mechanisms in the peritumoral bladder wall after bacillus Calmette-Guérin treatment," British Journal of Urology International, vol. 88, no. 6, pp. 602-610, 2001.

[27] E. C. De Boer, W. H. De Jong, A. P. M. Van der Meijden et al., "Leukocytes in the urine after intravesical BCG treatment for superficial bladder cancer. A flow cytofluorometric analysis," Urological Research, vol. 19, no. 1, pp. 45-50, 1991.

[28] E. C. De Boer, W. H. De Jong, A. P. M. Van der Meijden et al., "Presence of activated lymphocytes in the urine of patients with superficial bladder cancer after intravesical immunotherapy with bacillus Calmette-Guerin," Cancer Immunology Immunotherapy, vol. 33, no. 6, pp. 411-416, 1991.

[29] E. C. De Boer, W. H. De Jong, P. A. Steerenberg et al., "Leukocytes and cytokines in the urine of superficial bladder cancer patients after intravesical immunotherapy with Bacillus Calmette-Guerine," In Vivo, vol. 5, no. 6, pp. 671-678, 1991.

[30] A. Böhle, N. CH. Nowc, A. J. Ulmer et al., "Elevations of cytokines interleukin-1, interleukin-2 and tumor necrosis factor in the urine of patients after intravesical bacillus Calmette-Guerin immunotherapy," Journal of Urology, vol. 144, no. 1, pp. 59-64, 1990.

[31] G. N. Thalmann, A. Sermier, C. Rentsch, K. Möhrle, M. G. Cecchini, and U. E. Studer, "Urinary interleukin-8 and 18 predict the response of superficial bladder cancer to intravesical therapy with bacillus Calmette-Guerin," Journal of Urology, vol. 164, no. 6, pp. 2129-2133, 2000.

[32] T. M. De Reijke, E. C. De Boer, K. H. Kurth, and D. H. J. Schamhart, "Urinary cytokines during intravesical bacillus Calmette-Guerin therapy for superficial bladder cancer: processing, stability and prognostic value," Journal of Urology, vol. 155, no. 2, pp. 477-482, 1996.

[33] F. Saint, J. J. Patard, P. Maille et al., "Prognostic value of a T helper 1 urinary cytokine response after intravesical bacillus Calmette-Guerin treatment for superficial bladder cancer," Journal of Urology, vol. 167, no. 1, pp. 364-367, 2002.

[34] R. Nadler, Y. Luo, W. Zhao et al., "Interleukin 10 induced augmentation of delayed-type hypersensitivity (DTH) enhances Mycobacterium bovis bacillus Calmette-Guérin (BCG) mediated antitumour activity," Clinical and Experimental Immunology, vol. 131, no. 2, pp. 206-216, 2003.

[35] Y. Luo, X. Chen, and M. A. O’Donnell, “Mycobacterium bovis bacillus Calmette-Guérin (BCG) induces human CCand CXC-chemokines in vitro and in vivo," Clinical and Experimental Immunology, vol. 147, no. 2, pp. 370-378, 2007.

[36] J. Wang, J. Wakeham, R. Harkness, and Z. Xing, "Macrophages are a significant source of type 1 cytokines during mycobacterial infection," Journal of Clinical Investigation, vol. 103, no. 7, pp. 1023-1029, 1999.

[37] S. Atkinson, E. Valadas, S. M. Smith, P. T. Lukey, and H. M. Dockrell, "Monocyte-derived macrophage cytokine responses induced by M. bovis BCG," Tubercle and Lung Disease, vol. 80, no. 4-5, pp. 197-207, 2000.

[38] L. Calorini, F. Bianchini, A. Mannini et al., "IFN $\gamma$ and TNF $\alpha$ account for a pro-clonogenic activity secreted by activated murine peritoneal macrophages," Clinical and Experimental Metastasis, vol. 19, no. 3, pp. 259-264, 2002.

[39] J. Baran, M. Baj-Krzyworzeka, K. Weglarczyk, I. Ruggiero, and M. Zembala, "Modulation of monocyte-tumour cell interactions by Mycobacterium vaccae," Cancer Immunology, Immunotherapy, vol. 53, no. 12, pp. 1127-1134, 2004.

[40] K. Pryor, J. Goddard, D. Goldstein et al., "Bacillus CalmetteGuerin (BCG) enhances monocyte- and lymphocytemediated bladder tumour cell killing," British Journal of Cancer, vol. 71, no. 4, pp. 801-807, 1995.

[41] H. Yamada, S. Matsumoto, T. Matsumoto, T. Yamada, and U. Yamashita, "Murine IL-2 secreting recombinant Bacillus Calmette-Guerin augments macrophage-mediated cytotoxicity against murine bladder cancer MBT-2," Journal of Urology, vol. 164, no. 2, pp. 526-531, 2000.

[42] H. Yamada, S. Matsumoto, T. Matsumoto, T. Yamada, and U. Yamashita, "Enhancing effect of an inhibitor of nitric oxide synthesis on Bacillus Calmette-Guerin-induced macrophage cytotoxicity against murine bladder cancer cell line MBT-2 in vitro," Japanese Journal of Cancer Research, vol. 91, no. 5, pp. 534-542, 2000.

[43] H. Yamada, E. Kuroda, S. Matsumoto, T. Matsumoto, T. Yamada, and U. Yamashita, "Prostaglandin E2 down-regulates viable Bacille Calmette-Guérin-induced macrophage cytotoxicity against murine bladder cancer cell MBT-2 in vitro," Clinical and Experimental Immunology, vol. 128, no. 1, pp. 52$58,2002$.

[44] Y. Luo, H. Yamada, X. Chen et al., "Recombinant Mycobacterium bovis bacillus Calmette-Guérin (BCG) expressing mouse IL-18 augmente Th1 immunity and macrophage cytotoxicity," Clinical and Experimental Immunology, vol. 137, no. 1, pp. 24-34, 2004.

[45] Y. Luo, H. Yamada, D. P. Evanoff, and X. Chen, "Role of Th1stimulating cytokines in bacillus Calmette-Guérin (BCG)induced macrophage cytotoxicity against mouse bladder cancer MBT-2 cells," Clinical and Experimental Immunology, vol. 146, no. 1, pp. 181-188, 2006.

[46] Y. Luo, R. Han, D. P. Evanoff, and X. Chen, "Interleukin10 inhibits Mycobacterium bovis bacillus Calmette-Guérin (BCG)-induced macrophage cytotoxicity against bladder cancer cells," Clinical and Experimental Immunology, vol. 160, no. 3, pp. 359-368, 2010.

[47] T. L. Ratliff, "Bacillus Calmette-Guerin (BCG): mechanism of action in superficial bladder cancer," Urology, vol. 37, no. 5, supplement, pp. 8-11, 1991.

[48] R. F. M. Bevers, K.-H. Kurth, and D. H. J. Schamhart, "Role of urothelial cells in BCG immunotherapy for superficial bladder cancer," British Journal of Cancer, vol. 91, no. 4, pp. 607-612, 2004.

[49] W. L. Smith, R. M. Garavito, and D. L. DeWitt, "Prostaglandin endoperoxide H syntheses (cyclooxygenases)-1 and -2," Journal of Biological Chemistry, vol. 271, no. 52, pp. 33157-33160, 1996.

[50] J. Arnold, E. C. De Boer, M. A. O’Donnell, A. Böhle, and S. Brandau, "Immunotherapy of experimental bladder cancer with recombinant BCG expressing interferon- $\gamma$," Journal of Immunotherapy, vol. 27, no. 2, pp. 116-123, 2004.

[51] M. Horinaga, K. M. Harsch, R. Fukuyama, W. Heston, and W. Larchian, "Intravesical interleukin-12 gene therapy in an orthotopic bladder cancer model," Urology, vol. 66, no. 2, pp. 461-466, 2005.

[52] L. E. DesJardin, T. M. Kaufman, B. Potts, B. Kutzbach, H. Yi, and L. S. Schlesinger, "Mycobacterium tuberculosis-infected 
human macrophages exhibit enhanced cellular adhesion with increased expression of LFA-1 and ICAM-1 and reduced expression and/or function of complement receptors, Fc $\gamma$ RII and the mannose receptor," Microbiology, vol. 148, no. 10, pp. 3161-3171, 2002.

[53] T. Mustafa, S. Phyu, R. Nilsen, G. Bjune, and R. Jonsson, "Increased expression of Fas ligand on Mycobacterium tuberculosis infected macrophages: a potential novel mechanism of immune evasion by Mycobacterium tuberculosis?" Inflammation, vol. 23, no. 6, pp. 507-521, 1999.

[54] G. E. Diehl, H. H. Yue, K. Hsieh et al., "TRAIL-R as a negative regulator of innate immune cell responses," Immunity, vol. 21, no. 6, pp. 877-889, 2004.

[55] S. Saito and M. Nakano, "Nitric oxide production by peritoneal macrophages of Mycobacterium bovis BCG-infected or non-infected mice: regulatory roles of $\mathrm{T}$ lymphocytes and cytokines," Journal of Leukocyte Biology, vol. 59, no. 6, pp. 908915, 1996.

[56] V. L. Petricevich and R. C. B. Alves, "Role of cytokines and nitric oxide in the induction of tuberculostatic macrophage functions," Mediators of Inflammation, vol. 9, no. 6, pp. 261$269,2000$.

[57] S. J. Hawkyard, A. M. Jackson, S. Prescott, K. James, and G. D. Chisholm, "The effect of recombinant cytokines on bladder cancer cells in vitro," Journal of Urology, vol. 150, no. 2, pp. 514-518, 1993.

[58] S.-C. Choi, H.-M. Oh, J.-S. Park et al., "Soluble factor from murine bladder tumor-2 cell elevates nitric oxide production in macrophages and enhances the taxol-mediated macrophage cytotoxicity on tumor cells," Cancer Investigation, vol. 21, no. 5, pp. 708-719, 2003.

[59] M. A. O'Donnell, Y. Luo, S. E. Hunter, X. Chen, L. L. Hayes, and S. K. Clinton, "The essential role of interferon- $\gamma$ during interleukin-12 therapy for murine transitional cell carcinoma of the bladder," Journal of Urology, vol. 171, no. 3, pp. 13361342, 2004.

[60] C. F. Ware, S. VanArsdale, and T. L. VanArsdale, "Apoptosis mediated by the TNF-related cytokine and receptor families," Journal of Cellular Biochemistry, vol. 60, no. 1, pp. 47-55, 1996.

[61] S. M. Laster, J. G. Wood, and L. R. Gooding, "Tumor necrosis factor can induce both apoptic and necrotic forms of cell lysis," Journal of Immunology, vol. 141, no. 8, pp. 2629-2634, 1988.

[62] V. Umansky and V. Schirrmacher, "Nitric oxide-induced apoptosis in tumor cells," Advances in Cancer Research, vol. 82, pp. 107-131, 2001.

[63] S. J. Greent, L. F. Scheller, M. A. Marletta et al., "Nitric Oxide: cytokine-regulation of nitric oxide in host resistance to intracellular pathogens," Immunology Letters, vol. 43, no. 1-2, pp. 87-94, 1994.

[64] V. Kindler, A.-P. Sappino, G. E. Grau, P.-F. Piguet, and P. Vassalli, "The inducing role of tumor necrosis factor in the development of bactericidal granulomas during BCG infection," Cell, vol. 56, no. 5, pp. 731-740, 1989.

[65] A. Zhou, Z. Chen, J. A. Rummage et al., "Exogenous interferon- $\gamma$ induces endogenous synthesis of interferon- $\alpha$ and $-\beta$ by murine macrophages for induction of nitric oxide synthase," Journal of Interferon and Cytokine Research, vol. 15, no. 10, pp. 897-904, 1995.

[66] S. Huguenin, F. Vacherot, J. Fleury-Feith et al., "Evaluation of the antitumoral potential of different nitric oxide-donating non-steroidal anti-inflammatory drugs (NO-NSAIDs) on human urological tumor cell lines," Cancer Letters, vol. 218, no. 2, pp. 163-170, 2005.
[67] E. Morcos, O. T. Jansson, J. Adolfsson, G. Kratz, and N. Peter Wiklund, "Endogenously formed nitric oxide modulates cell growth in bladder cancer cell lines," Urology, vol. 53, no. 6, pp. 1252-1257, 1999.

[68] O. T. Jansson, E. Morcos, L. Brundin et al., "The role of nitric oxide in bacillus Calmette-Guérin mediated antitumour effects in human bladder cancer," British Journal of Cancer, vol. 78, no. 5, pp. 588-592, 1998.

[69] J. Riemensberger, A. Böhle, and S. Brandau, "IFN-gamma and IL-12 but not IL-10 are required for local tumour surveillance in a syngeneic model of orthotopic bladder cancer," Clinical and Experimental Immunology, vol. 127, no. 1, pp. 20-26, 2002.

[70] R. De Waal Malefyt, J. Abrams, B. Bennett, C. G. Figdor, and J. E. De Vries, "Interleukin 10(IL-10) inhibits cytokine synthesis by human monocytes: an autoregulatory role of IL10 produced by monocytes," Journal of Experimental Medicine, vol. 174, no. 5, pp. 1209-1220, 1991.

[71] D. F. Fiorentino, A. Zlotnik, T. R. Mosmann, M. Howard, and A. O'Garra, "IL-10 inhibits cytokine production by activated macrophages," Journal of Immunology, vol. 147, no. 11, pp. 3815-3822, 1991.

[72] E. Cenci, L. Romani, A. Mencacci et al., "Interleukin-4 and interleukin-10 inhibit nitric oxide-dependent macrophage killing of Candida albicans," European Journal of Immunology, vol. 23, no. 5, pp. 1034-1038, 1993.

[73] C. Bogdan, Y. Vodovotz, and C. Nathan, "Macrophage deactivation by interleukin 10," Journal of Experimental Medicine, vol. 174, no. 6, pp. 1549-1555, 1991.

[74] P. Chomarat, J. Banchereau, J. Davoust, and A. K. Palucka, "IL-6 switches the differentiation of monocytes from dendritic cells to macrophages," Nature Immunology, vol. 1, no. 6, pp. 510-514, 2000. 


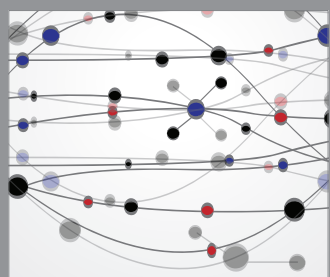

The Scientific World Journal
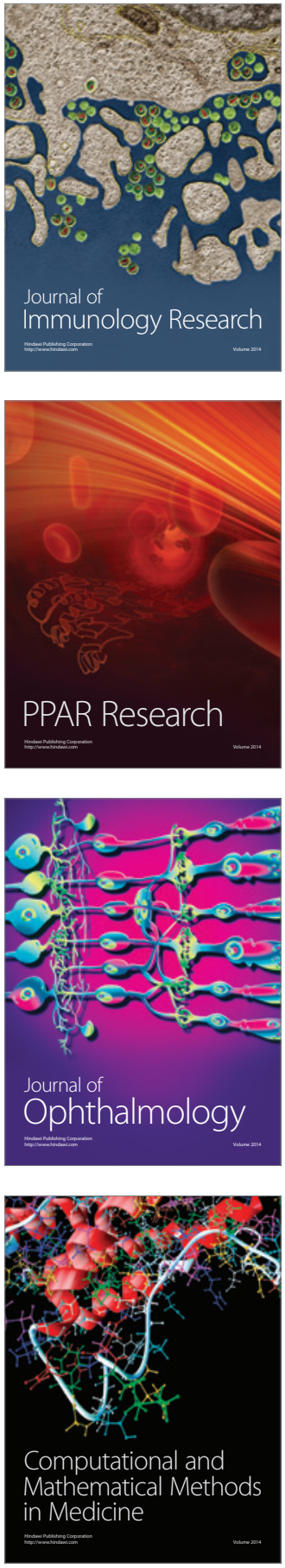

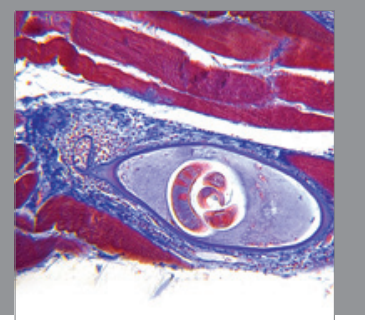

Gastroenterology

Research and Practice
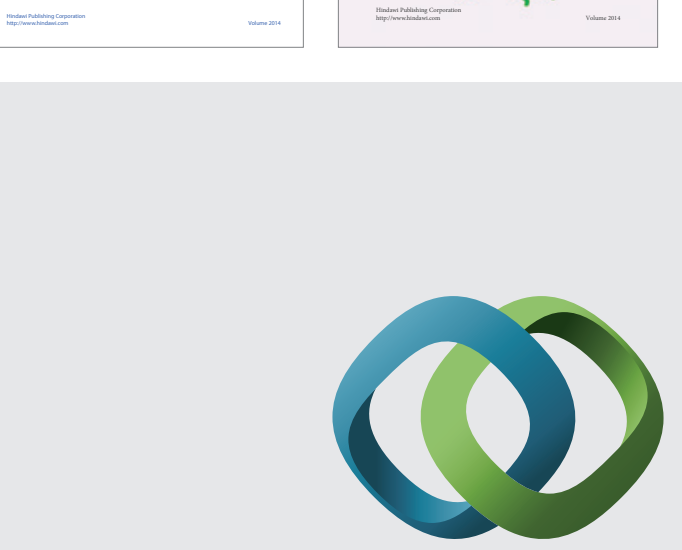

\section{Hindawi}

Submit your manuscripts at

http://www.hindawi.com
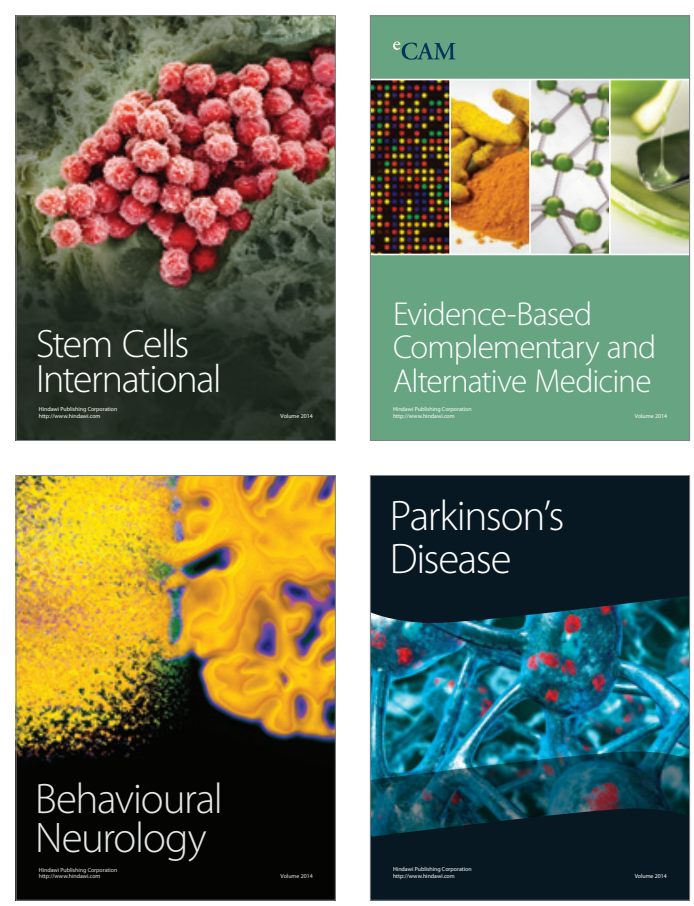

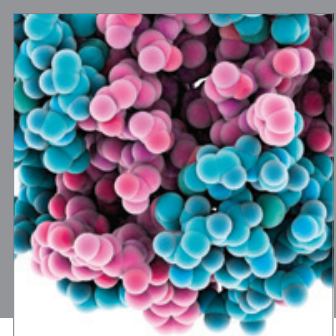

Journal of
Diabetes Research

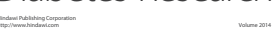

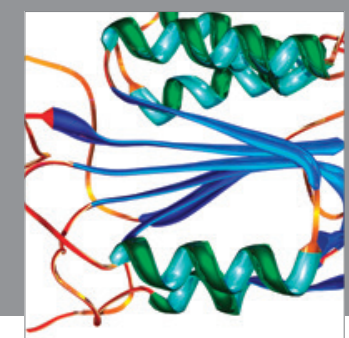

Disease Markers
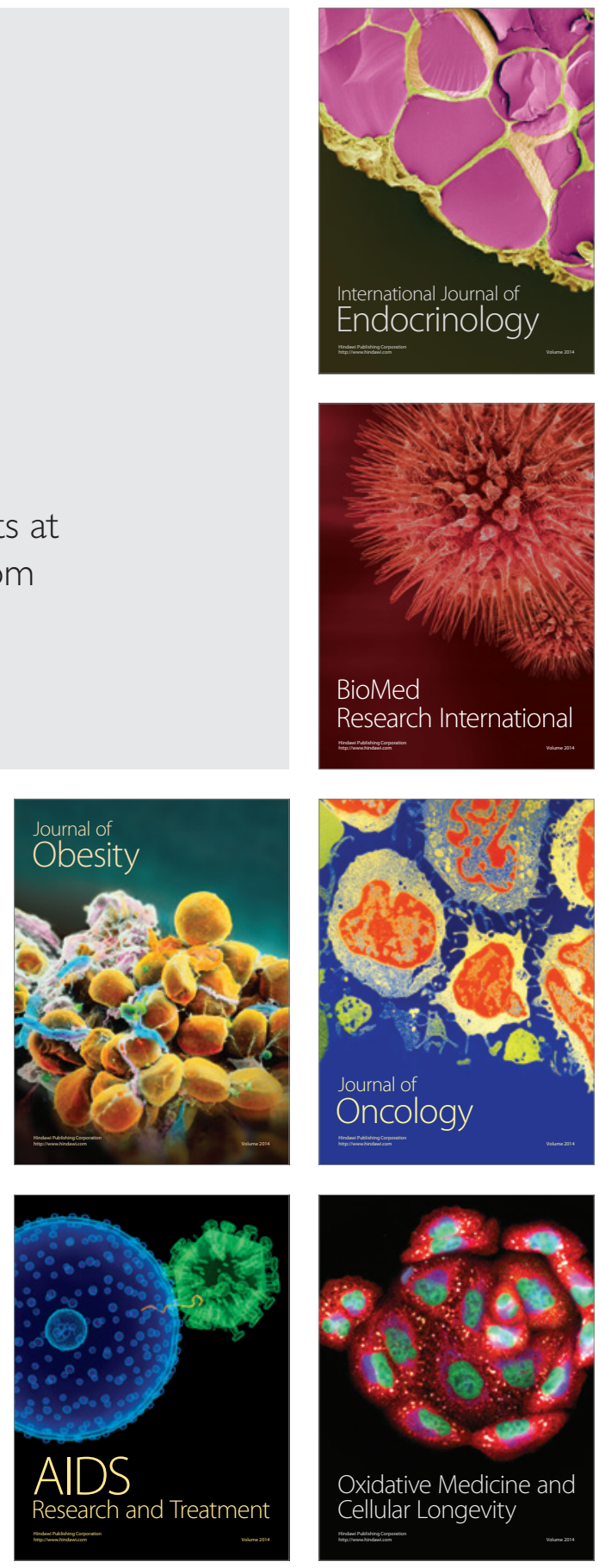